\title{
Lean Mining Analysis in Gold Mining Use Waste Assessment Model
}

\author{
Liga Indriyani ${ }^{1}$ and Moses Laksono Singgih ${ }^{2}$ \\ ${ }^{1}$ Department of Management Technology, Institut Teknologi Sepuluh Nopember, Surabaya. \\ ${ }^{2}$ Department of Industrial Engineering, Institut Teknologi Sepuluh Nopember, Surabaya \\ e-mail: ligaindriyani027@gmail.com
}

\begin{abstract}
This research identifies non-value added activities and minimizes waste in the production process at a gold mine. Problems that occur include the presence of waste defects in the form of choke ore materials, mismatches in dore bullion printing, and equipment damage. Then the waste waiting caused by low-level bin ore and the presence of ponding during leaching. In addition, there is also waste over processing in the form of carbon regeneration and transportation processes in the form of altered and distant ore transportation distances. The occurrence of waste can be reduced/eliminated using the Lean Mining approach which is a method to streamline the process by eliminating/reducing the presence of waste in the mining process. Identify waste using the Waste Assessment Model (WAM) tools. The results of the analysis show that the highest waste rating is a defect, motion, waiting, and process with successive percentages of the largest i.e. $20.75 \%, 18.42 \%$, $17.57 \%$, and $14.36 \%$. From these results then recommendations for improvements that can be proposed are controlling the size and composition of ore-sized mixtures, increasing the efficiency of the crusher using TPM analysis, optimizing maintenance, making machines/systems automatically filling gold solutions, and making standardized work.
\end{abstract}

Keywords-Lean, Lean Mining, Gold Mining, Waste, Waste Assessment Model.

\section{INTRODUCTION}

$\mathrm{T}$ HE development of the industry by conducting research related to the improvement or improvement of the quality and quantity of products and the efficiency of the production process is one way to advance an industry. However, companies often face problems, such as product quality degradation, equipment damage, scheduling delays, and human resource control so it is important that a company has a fast and precise control system in order to overcome existing problems and meet customer/market demand.

One industry that has a business area with high market demand is the mining industry, especially gold mining. Even though the production output from mining companies will be totally absorbed by the market. While large market needs, often make mining companies exceed their production capacity. Then the increase in production output in the mining area will greatly affect the revenue and profit of a mining company.

In increasing production capacity, mining companies need to make improvements to make the production process more efficient by reducing the activities that cause waste. Waste in the industry is defined as anything that does not add value to the final product. The types of waste include transportation, over processing, motion, work in process, waiting for time, overproduction, and defects [1].

At the gold mining company, the process stages are divided into 4 process stages, namely the Mining Infrastructure Area (MIA), Ore Preparation Plant (OPP), Heap Leach Operation (HLO) and Adsorption Desorption Recovery (ADR) plants. From all stages of the gold production process or Dore Bullion, there are waste problems that interfere with the production process.

Based on preliminary observations made, there are several waste activities that occur at the Operation Processing Plant (OPP) stage, namely the type of waste defect and waiting. Defects that occur are the presence of choke material or the retention of ore material in the crusher because of the uniform size of the ore material. This resulted in a breakdown during the production process. then waste waiting that occurs in the form of a low-level bin. This problem is due to delays in ore shipments from the mining area to OPP. This makes the production process must be delayed temporarily so this needs to be reduced or anticipated from the beginning so that production can run effectively.

Subsequent initial observations made at the Heap Leach Operation (HLO) stage were found to be waste transportation and waiting. This waste transportation is in the form of the distance of the transport of agglomerates from the stockpile in OPP to the stacking area in the HLO section. Because the stacking area moves around the place, so the company must prepare the appropriate dump truck transportation. However, sometimes there is idling for some dump trucks because it does not carry out the transportation process at all. The stacking area studied this time is lift 5 on bay 9 , so with a transport capacity of 40 tons per dump truck requires a transport cycle time of about 26 minutes. The next waste is in the form of waiting, namely ponding during the irrigation process to produce Pregnant Leach Solution (PLS) and Intermediate Leach Solution (ILS). Ponding is the occurrence of standing water in the irrigation flow so that the irrigation process cannot run optimally. This waste causes the process to stop temporarily to deal with this problem by re-ripping or re-agglomerating which will be irrigated.

The next waste that occurs at the Adsorption Desorption Recovery (ADR) stage is over processing and defect. The problem of waste over processing is in the form of the length of the cycle time for the carbon regeneration process that is used to adsorb Pregnant Leach Solution (PLS) so that this causes a cycle time incompatibility of the carbon regeneration process with the adsorption process. Before the carbon 


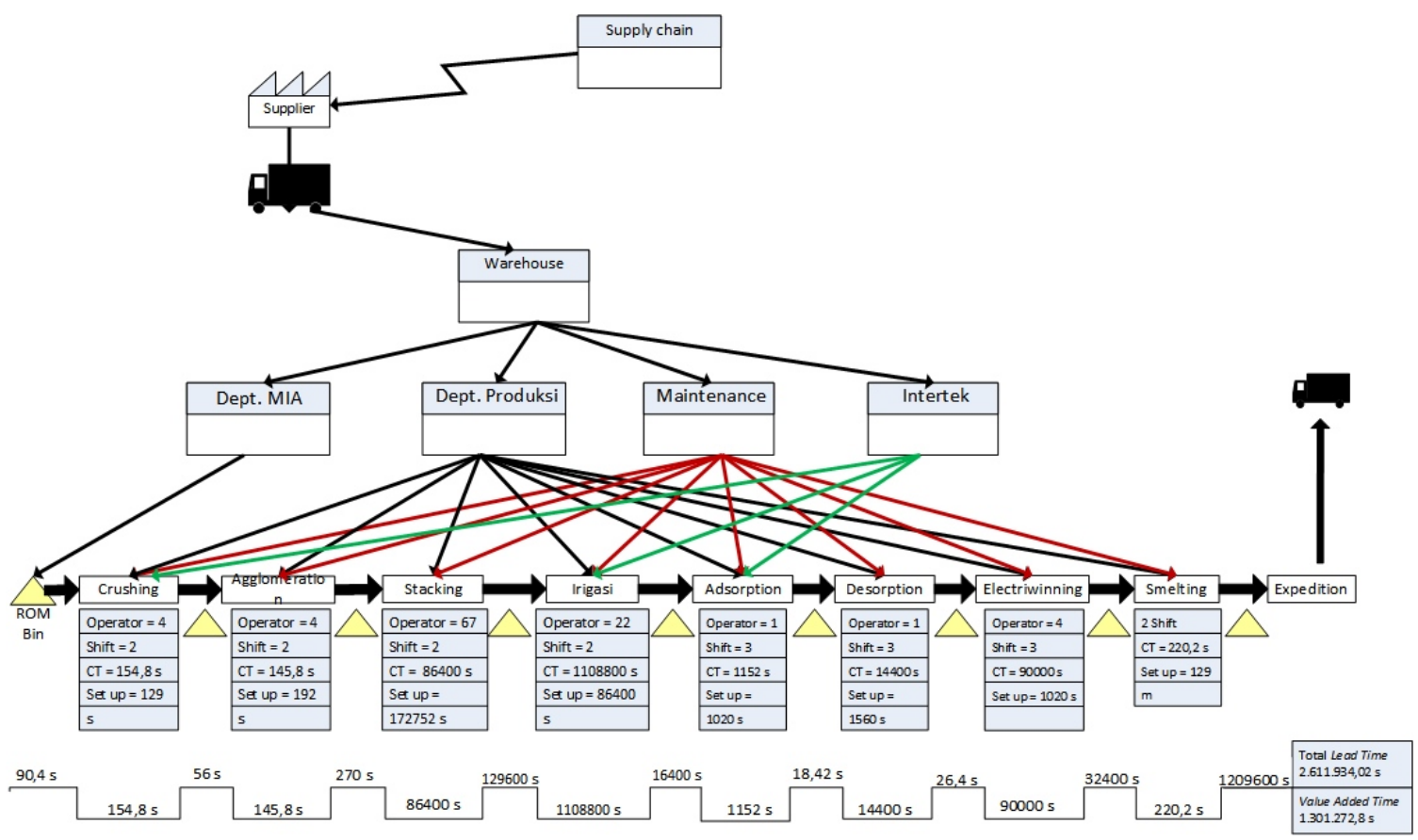

Figure 1. Big Picture Mapping Dore Bullion Production Process.

Table 1.

Waste Relationship Matrix (WRM).

\begin{tabular}{cccccccc}
\hline F/T & O & WIP & D & M & T & P & W \\
\hline O & A & I & I & I & I & X & O \\
I & I & A & I & I & I & X & X \\
D & I & I & A & I & O & X & E \\
M & X & O & O & A & X & I & O \\
T & O & O & O & O & A & X & O \\
P & I & I & I & I & X & A & O \\
W & O & I & O & X & X & X & A \\
\hline \hline
\end{tabular}

Table 2.

Waste Value Matrix

\begin{tabular}{cccccccccc}
\hline \hline F/T & O & WIP & D & M & T & P & W & SKOR & \% \\
\hline O & 10 & 6 & 6 & 6 & 6 & 0 & 4 & 38 & 16.38 \\
WIP & 6 & 10 & 6 & 6 & 6 & 0 & 0 & 34 & 14.66 \\
$\mathbf{D}$ & 6 & 6 & 10 & 6 & 4 & 0 & 8 & 40 & 17.24 \\
$\mathbf{M}$ & 0 & 4 & 4 & 10 & 0 & 6 & 4 & 28 & 12.07 \\
$\mathbf{T}$ & 4 & 4 & 4 & 4 & 10 & 0 & 4 & 30 & 12.93 \\
$\mathbf{P}$ & 6 & 6 & 6 & 6 & 0 & 10 & 4 & 38 & 16.38 \\
$\mathbf{W}$ & 4 & 6 & 4 & 0 & 0 & 0 & 10 & 24 & 10.34 \\
SKOR & 36 & 42 & 40 & 38 & 26 & 16 & 34 & 232 & 100 \\
$\mathbf{\%}$ & 15.52 & 18.1 & 17.24 & 16.38 & 11.21 & 6.9 & 14.66 & 100 & \\
\hline \hline
\end{tabular}

regeneration process is complete, the carbon must be taken for the adsorption process. If this continues, the ability of carbon sequestration will be reduced and the operator must also always do the extra work to move carbon from the regeneration process to adsorption without a clear standard transfer time. Then the waste defect at the ADR stage is the discrepancy of the printed gold bar or Dore Bullion. This makes the Dore Bullion product must experience rework to overcome the form of Dore Bullion that is not the same as the print. This waste makes the repetition of jobs in printing Dore Bullion and increases production time and costs.
Table 3.

Grouping Questionnaire Types.

\begin{tabular}{clc}
\hline \hline No. & \multicolumn{1}{c}{ Type of Questions (i) } & Total (Ni) \\
\hline 1. & From Overproduction & 3 \\
2. & From WIP & 6 \\
3. & From Defects & 8 \\
4. & From Motion & 11 \\
5. & From Transportation & 4 \\
6. & From Process & 7 \\
7. & From Waiting & 8 \\
8. & To Defects & 4 \\
9. & To Motion & 9 \\
10. & To Transportation & 3 \\
11. & To Waiting & Total of Questions \\
\end{tabular}

In addition to the problems he mentioned above, problems that often occur but are considered to be an ordinary thing namely waste motion. This waste occurs because of unnecessary or excessive movement. For example, an operator who is walking takes equipment, non-compliance of workers in carrying out work duties and taking oversized ore material that is far away.

So that the process can run more effectively and efficiently, it is necessary to improve alternatives to overcome the above wastes. The ideal method to be applied in making improvements from waste one of which is the Lean method. This method is useful to reduce the waste in all stages of the production process carried out by identifying the existence of non-value added activities (activities that do not add value to the product but are still being carried out)[2]. Lean is a method of streamlining or process efficiency to eliminate/reduce waste or waste. In business philosophy, the Lean method is based on minimizing or reducing the use of 
Table 4.

Distribution of Question Weights.

\begin{tabular}{|c|c|c|c|c|c|c|c|c|c|c|}
\hline \multirow{2}{*}{ No. } & \multirow{2}{*}{ Category } & \multirow{2}{*}{ Type } & \multirow{2}{*}{$\mathbf{N i}$} & \multicolumn{7}{|c|}{ Initial Weight of each waste } \\
\hline & & & & $\mathbf{W}_{\mathbf{0 , k}}$ & $\mathbf{W}_{\text {WIP,k }}$ & $\mathbf{W}_{\mathrm{d}, \mathrm{k}}$ & $\mathbf{W}_{\mathbf{m}, \mathbf{k}}$ & $\mathbf{W}_{\mathrm{t}, \mathrm{k}}$ & $\mathbf{W}_{\mathbf{p}, \mathbf{k}}$ & $\mathbf{W}_{\mathbf{w}, \mathbf{k}}$ \\
\hline 1 & \multirow{7}{*}{ Man } & To M & 9 & 0.67 & 0.67 & 0.67 & 1.11 & 0.44 & 0.67 & 0 \\
\hline 2 & & From M & 11 & 0 & 0.36 & 0.36 & 0.91 & 0 & 0.55 & 0.36 \\
\hline 3 & & From D & 8 & 0.75 & 0.75 & 1.25 & 0.75 & 0.5 & 0 & 1 \\
\hline 4 & & From M & 11 & 0 & 0.36 & 0.36 & 0.91 & 0 & 0.55 & 0.36 \\
\hline 5 & & From $\mathrm{M}$ & 11 & 0 & 0.36 & 0.36 & 0.91 & 0 & 0.55 & 0.36 \\
\hline 6 & & From D & 8 & 0.75 & 0.75 & 1.25 & 0.75 & 0.5 & 0 & 1 \\
\hline 7 & & From P & 7 & 0.86 & 0.86 & 0.86 & 0.86 & 0 & 1.43 & 0.57 \\
\hline 64 & \multirow{5}{*}{ Method } & From $\mathrm{M}$ & 11 & 0 & 0.36 & 0.36 & 0.91 & 0 & 0.55 & 0.36 \\
\hline 65 & & From M & 11 & 0 & 0.36 & 0.36 & 0.91 & 0 & 0.55 & 0.36 \\
\hline 66 & & From $\mathrm{O}$ & 5 & 2 & 1.2 & 1.2 & 1.2 & 1.2 & 0 & 0.8 \\
\hline 67 & & From P & 7 & 0.86 & 0.86 & 0.86 & 0.86 & 0 & 1.43 & 0.57 \\
\hline 68 & & From D & 8 & 0.75 & 0.75 & 1.25 & 0.75 & 0.5 & 0 & 1 \\
\hline \multicolumn{4}{|c|}{ Scor $(\mathrm{Sj})$} & 54 & 57.6 & 65.6 & 53.6 & 45.6 & 32 & 46.4 \\
\hline \multicolumn{4}{|c|}{ Frequency $(\mathrm{Fj})$} & 54 & 87 & 54 & 64 & 42 & 43 & 33 \\
\hline
\end{tabular}

Table 5 .

Multiplication between Weight and Questionnaire Answer Value

\begin{tabular}{|c|c|c|c|c|c|c|c|c|c|c|}
\hline \multirow{2}{*}{ No. } & \multirow{2}{*}{ Category } & \multirow{2}{*}{ Type } & \multirow{2}{*}{$\mathbf{X}_{\mathbf{k}}$} & \multicolumn{7}{|c|}{ Weight Value for Each Waste } \\
\hline & & & & $\mathbf{W}_{\mathbf{0}, \mathbf{k}}$ & $\mathbf{W}_{\text {WIP,k }}$ & $\mathbf{W}_{\mathrm{d}, \mathrm{k}}$ & $\mathbf{W}_{\mathbf{m}, \mathbf{k}}$ & $\mathbf{W}_{\mathrm{t}, \mathrm{k}}$ & $\mathbf{W}_{\mathbf{p}, \mathbf{k}}$ & $\mathbf{W}_{\mathrm{w}, \mathrm{k}}$ \\
\hline 1 & \multirow{7}{*}{ Man } & To M & 1 & 0.67 & 0.67 & 0.67 & 1.11 & 0.44 & 0.67 & 0 \\
\hline 2 & & From M & 0.17 & 0 & 0.06 & 0.06 & 0.15 & 0 & 0.09 & 0.06 \\
\hline 3 & & From D & 0.17 & 0.13 & 0.13 & 0.21 & 0.13 & 0.08 & 0 & 0.17 \\
\hline 4 & & From M & 0.79 & 0 & 0.29 & 0.29 & 0.72 & 0 & 0.43 & 0.29 \\
\hline 5 & & From M & 0.71 & 0 & 0.26 & 0.26 & 0.64 & 0 & 0.39 & 0.26 \\
\hline 6 & & From D & 0.08 & 0.06 & 0.06 & 0.1 & 0.06 & 0.04 & 0 & 0.08 \\
\hline 7 & & From P & 0.04 & 0.04 & 0.04 & 0.04 & 0.04 & 0 & 0.06 & 0.02 \\
\hline 64 & \multirow{5}{*}{ Method } & From M & 0.5 & 0 & 0.18 & 0.18 & 0.45 & 0 & 0.27 & 0.18 \\
\hline 65 & & From M & 0.08 & 0 & 0.03 & 0.03 & 0.08 & 0 & 0.05 & 0.03 \\
\hline 66 & & From $\mathrm{O}$ & 0.88 & 1.75 & 1.05 & 1.05 & 1.05 & 1.05 & 0 & 0.7 \\
\hline 67 & & From P & 0.92 & 0.79 & 0.79 & 0.79 & 0.79 & 0 & 1.31 & 0.52 \\
\hline 68 & & From D & 0 & 0 & 0 & 0 & 0 & 0 & 0 & 0 \\
\hline \multicolumn{4}{|c|}{ new score (sj) } & 18.18 & 19.913 & 21.23 & 18.775 & 13.194 & 10.277 & 18.01 \\
\hline \multicolumn{4}{|c|}{ new frequency (fj) } & 8 & 11 & 13 & 19 & 8 & 19 & 11 \\
\hline
\end{tabular}

resources (including time) in various activities and focusing on identifying and eliminating activities that do not add value (non-value added activities)[1]. By adopting the tools commonly used for lean manufacturing, the tool that is applied to lean mining in gold mining companies this time is the Waste Assessment Model (WAM)[3]. This model is a waste settlement model by knowing the relationship between waste and presenting waste ratings that occur.

\section{METHOD}

The method used includes steps arranged systematically and structured in order to get optimal results that are formed into a research methodology. The flow of research phases made for this research as a step guide in conducting research consisting of problem identification, problem formulation, data collection, data analysis, data processing, and conclusions and suggestions. The following explains the specific stages of the research:

\section{A. Data Collection}

In this study using two types of data, namely primary data and secondary data. Primary data were obtained from direct observation, interviews, and the results of questionnaires. The first step taken was to conduct an interview with the production department about the dore bullion production process. Then the discussion about the waste that occurs at all stages of the dore bullion production process. The list of waste that has been obtained, is used as a reference in making a questionnaire that is the Waste Relationship Matrix (WRM) and Waste Assessment Questionnaire (WAQ). WRM questionnaire to measure the relationship between waste and 
The $1^{\text {st }}$ International Conference on Business and Engineering Management (IConBEM)

February $1^{\text {st }}$ 2020, Institut Teknologi Sepuluh Nopember, Surabaya, Indonesia

Table 6.

Initial Indicator Values (Yj).

\begin{tabular}{cccccccc}
\hline \hline & $\mathrm{O}$ & $\mathrm{WIP}$ & $\mathrm{D}$ & $\mathrm{M}$ & $\mathrm{T}$ & $\mathrm{P}$ & $\mathrm{W}$ \\
\hline $\mathrm{Sj}$ & 54 & 57.6 & 65.6 & 53.6 & 45.6 & 32 & 46.4 \\
$\mathrm{Fj}$ & 54 & 87 & 54 & 64 & 42 & 43 & 33 \\
$\mathrm{sj}$ & 18.18 & 19.91 & 21.23 & 18.78 & 13.19 & 10.28 & 18.01 \\
$\mathrm{fj}$ & 8 & 11 & 13 & 19 & 8 & 19 & 11 \\
$\mathrm{Yj}$ & 0,05 & 0.04 & 0.08 & 0.1 & 0.06 & 0.14 & 0.13 \\
\hline \hline
\end{tabular}

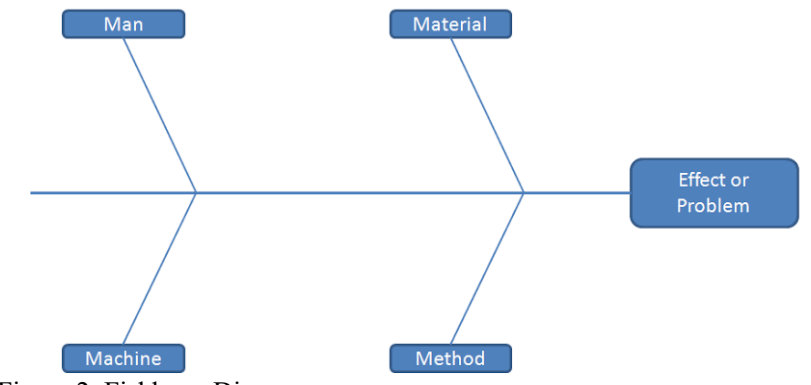

Figure 2. Fishbone Diagram

Table 7.

Results of Waste Assessment Calculations

\begin{tabular}{|c|c|c|c|c|c|c|c|}
\hline & $\mathrm{O}$ & WIP & $\mathrm{D}$ & M & $\mathrm{T}$ & $\mathrm{P}$ & W \\
\hline $\mathrm{Yj}$ & 0.05 & 0.04 & 0.08 & 0.1 & 0.06 & 0.14 & 0.13 \\
\hline Pj faktor & 254.16 & 265.31 & 297.27 & 197.68 & 144.92 & 112.96 & 151.61 \\
\hline Yj Final & 12.68 & 11.6 & 23.16 & 20.56 & 7.99 & 16.03 & 19.62 \\
\hline Hasil Akhir (\%) & 11.36 & 10.39 & 20.75 & 18.42 & 7.16 & 14.36 & 17.57 \\
\hline Ranking & 5 & 6 & 1 & 2 & 7 & 4 & 3 \\
\hline
\end{tabular}

the effect of waste on other waste [4]. The following is a list of WRM questionnaire questions:

1. Did i produce $\mathrm{j}$ ?

2. What is the type of relationship between $i$ and $j$ ?

3. Impact $j$ caused by $i$

4. Eliminating the effect $\mathrm{i}$ on $\mathrm{j}$ can be achieved by?

5. The effect on $\mathrm{j}$ because $\mathrm{i}$, mainly affects on?

6. At what rate does effect $\mathrm{i}$ on $\mathrm{j}$ increase lead time?

I is an abbreviation of all types of waste which has an effect on other types of waste. The WAQ questionnaire consisted of 68 questions. Each question has a different type and represents all activities, conditions, and behaviors in the production process that can produce waste. The questions are divided into 2 groups namely the type of question "from" and the type of question "to" and categorized into groups of questions man, machine, material, a method [5].

\section{B. Data Processing}

The data that has been obtained from the previous stage then used as a reference to make a big picture mapping. Big picture mapping is a tool used to describe a system as a whole that is accompanied by a value stream contained in a company or organization[6]. Then do the WRM and WAQ questionnaire results.

\section{Data Analysis and Discussion.}

This stage is done by interpreting the results of data processing Waste Relationship Matrix (WAM) and Waste Assessment Questionnaire (WAQ) from which the analysis has resulted in the ranking of each waste. Then analyze the result data from fishbone diagrams that get various lists of causes of each waste. The results of the fishbone diagram are used to help formulate alternative waste improvement recommendations.

\section{Conclusion}

Making conclusions based on several methods used in analyzing or conducting this research. From the conclusions that have been obtained, proceed with giving suggestions to the next researcher and alternative suggestions for improvements to minimize waste to the company so that the dore bullion production process can run more efficiently.

\section{RESULT AND DISCUSSION}

\section{A. Analysis Results}

The initial analysis results are a description of the physical flow and information presented in the form of big-picture mapping in Figure 1.

\section{1) Waste Relationship Matrix (WRM)}

From the results of the WRM questionnaire, the score is calculated for each question and grouping the level of interrelation between waste with the provisions:

Value A = absolutely necessary (score 17-20)

Value B = Especially Important (score 13-16)

Value I= Important (score 9-12)

Value $\mathrm{O}=$ Ordinary Closeness (score 5-8)

Value $\mathrm{U}=$ Unimportant (score 1-4)

The row in the WRM matrix above shows a waste that affects other waste, while the column side shows a waste that is affected by other types of waste. On the diagonal row marked with different colors, has the highest value of connection/relationship because waste that has a relationship with itself will always have the highest value of connection/relationship. Category of waste level in the form of letter symbols in Table 1, then converted into numbers with values $\mathrm{A}=10, \mathrm{E}=8, \mathrm{I}=6, \mathrm{O}=4, \mathrm{U}=2, \mathrm{X}=0$. The results of the conversion are shown in the Table 2.

2) Waste Assessment Questionnaire (WAQ)

Waste Assessment Questionnaire (WAQ) is used to determine the most influential waste to a production process based on the results of the assessment of the percentage of waste. The results of the values in Table 2 are used as initial weights in the WAQ calculation. The WAQ questionnaire consisted of 68 questions and was given to 12 respondents including the head department, superintendent, supervisor, and operator. Each answer choice in each question weighs 1; 


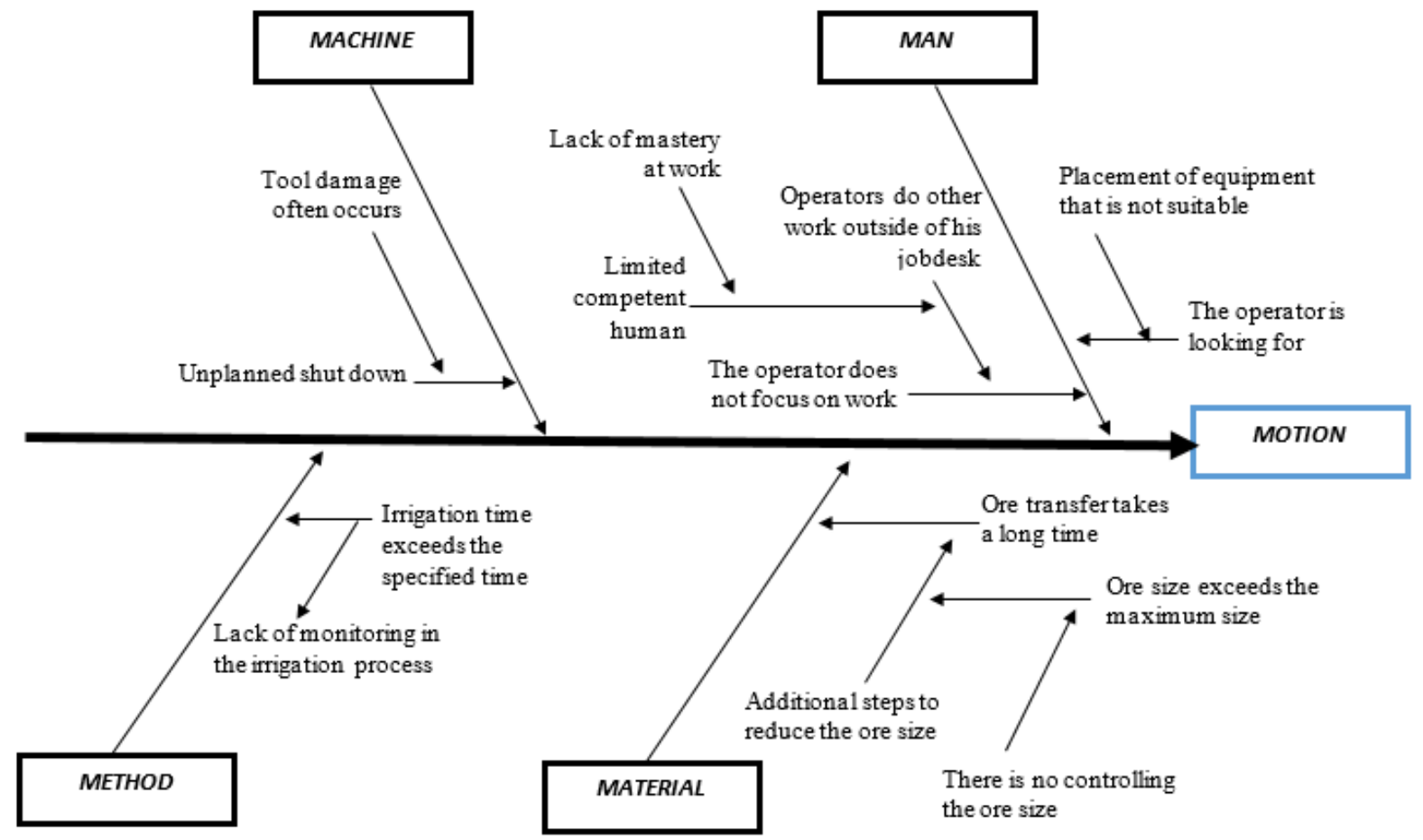

Figure 3. Fishbone Diagram of Defects

0.5; 0 for the answer choices "Yes", "Medium" and "No"[8]. Of the 68 questions on the WAQ questionnaire, they were grouped according to the types of questions as seen in Table 3.

The values in Table 2 and Table 3 are used as weight calculations in the waste assessment. The following is the formula for calculating weights:

$W j, k=\frac{\text { value } j, k \text { matrix }}{N i}$

After that, calculate the total score $(\mathrm{Sj})$ and frequency $(\mathrm{Fj})$ for each waste by calculating as follows:

$S_{j}=\sum_{K=1}^{K} \frac{W j, k}{N i}$

Frequency calculation is done by ignoring the value of zero (0) in each waste column,

After getting the results like the table above, then we calculate the average answer value from the WAQ questionnaire involving 12 respondents and calculate the new score ( $\mathrm{sj}$ ) and new frequency (fj).

$s_{j}=\sum_{K=1}^{K} X_{k} x \frac{W j, k}{N i}$

$\mathrm{Sj}=$ new score for this type of waste

$\mathrm{X}_{\mathrm{k}}=$ the average value of the questionnaire answers

The results of the assessment score of the relationship between waste are used as initial values in making the Waste Relationship Matrix (WRM) (sees Table 5) [7].

The next calculation is to calculate the value of the initial indicator $(\mathrm{Yj})$ for each waste using the following equation:

$Y_{j}=\frac{s_{j}}{s_{j}} x \frac{f_{j}}{F_{j}}$

The results of the Table 6 values are used to calculate the final $\mathrm{Yj}$ value using the following equation:
$Y_{j}$ final $=Y_{j} x P_{j}$

The $\mathrm{Pj}$ value in the above equation is the probability of influence between waste and is obtained by multiplying the percentage of waste value matrix results in rows and columns for each type of waste. Table 7 are the results of the final $\mathrm{Yj}$ calculation.

The results from the final $\mathrm{Yj}$ above are then used as a ranking of waste from the highest to the lowest. Based on Table 7, the obtained waste which has the highest percentage of $20.75 \%$, namely waste defect. Then the waste ranking below that is waste motion with a percentage of $18.42 \%$, waste waiting with a percentage of $17.57 \%$, and waste process with a percentage of $14.36 \%$. The four types of waste are wastes that affect the production process of dore bullion because they have a high percentage of waste assessment so that improvements are needed that can overcome the waste.

3) Root Cause Analysis

Root Cause Analysis (RCA) is a method used to solve a problem by looking for the actual cause of the problem. This method is also used to eliminate the causes of problems that occur or to prevent an unwanted problem from happening again [9].

One tool that can be used to analyze the root cause of a problem is the fishbone diagram. Fishbone diagrams are diagrams that show systematically the relationship between specific results and their causes. Fishbone diagrams are shaped like fish bones, qualitative characteristics are located on the head and the cause lies in the branches or thorns [10].

The four wastes that have the highest percentage, namely defect, motion, waiting, and process are then analyzed the root causes of the occurrence of waste which will be used as a reference to determine alternative improvements in eliminating the occurrence of waste. 
The $1^{\text {st }}$ International Conference on Business and Engineering Management (IConBEM)

February $1^{\text {st }} 2020$, Institut Teknologi Sepuluh Nopember, Surabaya, Indonesia

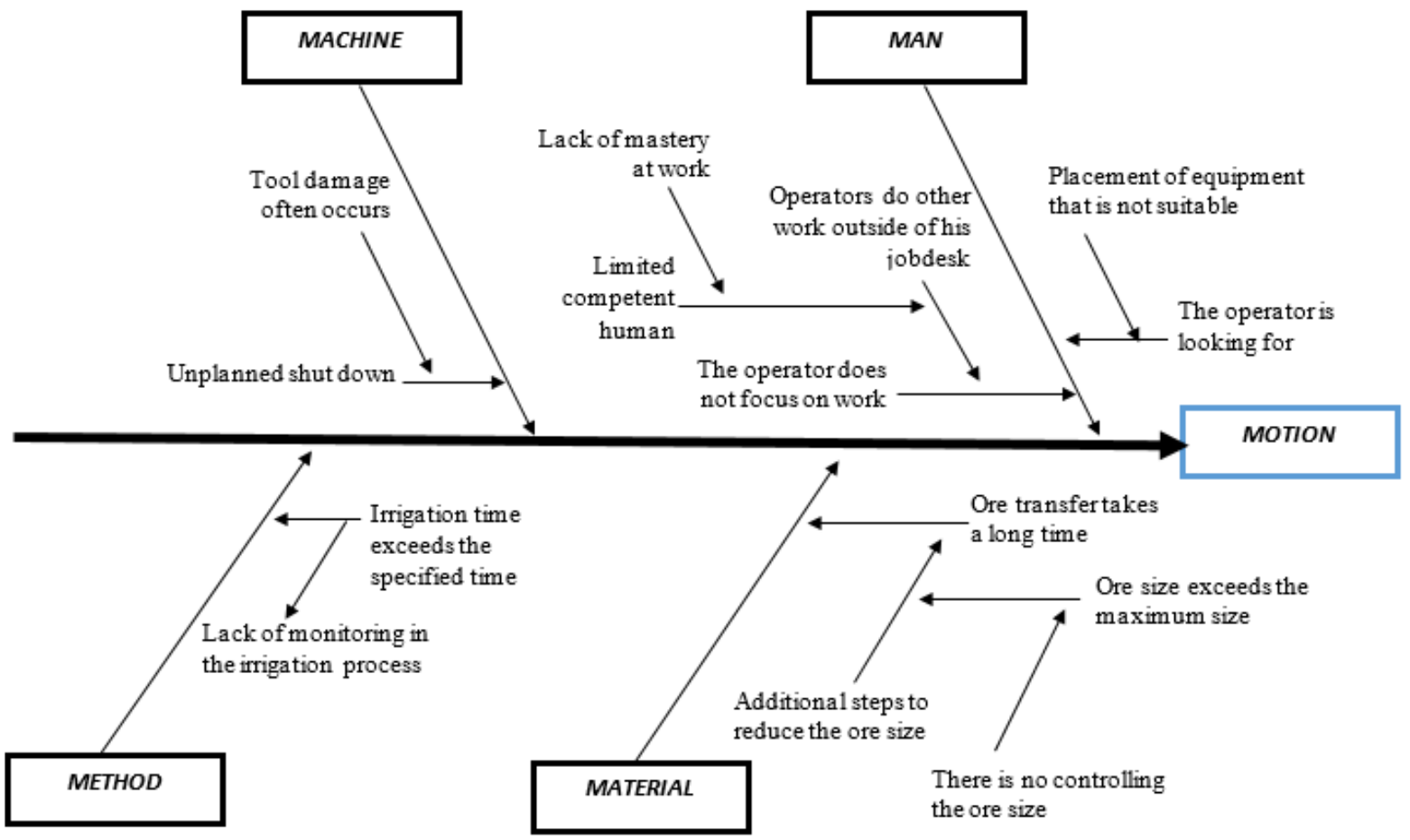

Figure 4. Fishbone Diagram of Motion

The four wastes above are analyzed by using the diagram shown in Figure 2. Root cause analysis is carried out based on four categories, namely man, material, machine, and method. The results of the fishbone diagram analysis for each waste are as follows:

\section{a. Defects}

Defects that occur in the dore bullion production process are related to producing results that do not match the mold shape and composition of dore bullion sizes that are uniform or the same. In addition, defects that occur in this process are also associated with the occurrence of damage to the tool.

In the man category, the cause of the problem is that the product handling is not optimal. This is because of the operator's negligence in printing dore bullion. This negligence is due to the lack of operator accuracy inflowing the gold solution into the dore bullion mold so that the root cause of the problem is found, namely the absence of material handling training. Therefore, this is needed an appropriate solution to deal with defect problems caused by man.

In the material category, it is caused by 2 things, namely the choke material and the printed dore bullion not as desired. Choke material can occur due to uniform ore size. The existence of this choke material will affect the downtime in the production process. While the mismatch of the print is caused by the gold solution to be printed will quickly solidify. This can be due to the dore bullion form factor that is made stacked and open. Because, if the mold is open it will come into contact with air which will further accelerate compaction.

The cause of problems in the machine category is downtime or break down. This is because the ability of the crusher to reduce the size decreases so that the ore that escapes or exits the crusher has a larger size or exceeds the desired size. While the cause of the problem in the method category is the printing process that is done manually by an operator. Treat this as a potential defect because the molding process is based on feeling. There is also another cause of the method, which is the absence of controlling the composition of the ore mixture from mining. So, ore results from mining are directly sent to the OPP for processing. When the ore is processed in OPP, problems often occur too large and or the size of ore transferred to the OPP is uniform or the same size which causes choke material.

\section{b. Motion}

Motion waste is one type of waste that often occurs in a production process. However, the existence of this waste is often ignored by the company because it is considered an ordinary thing that is done or even considered as part of the process.

In the man category, which causes unnecessary movements is caused by operators who are not focused on working. This happens because the operator is doing other work but not the job desk or this operator is helping the work of other workers. The reason the operator did that was because of the limitations of competent HR. The cause of this less competent HR is because the HR lacks mastery of his work so that an alternative is needed that can provide an understanding of $\mathrm{HR}$ about his job desk, work responsibilities, and mastery of the job. In addition, another cause of the man category is the presence of operators looking for process equipment due to improper placement arrangements or equipment being placed in an undesired place.

In the material category, the cause that causes motion is the material transfer activity that takes a long time. This is due to the presence of large ore from mining which is sent to OPP. Then, the mining operator must carry out the ore extraction activity to be brought to mining again, then the ore will be reduced in size again. 


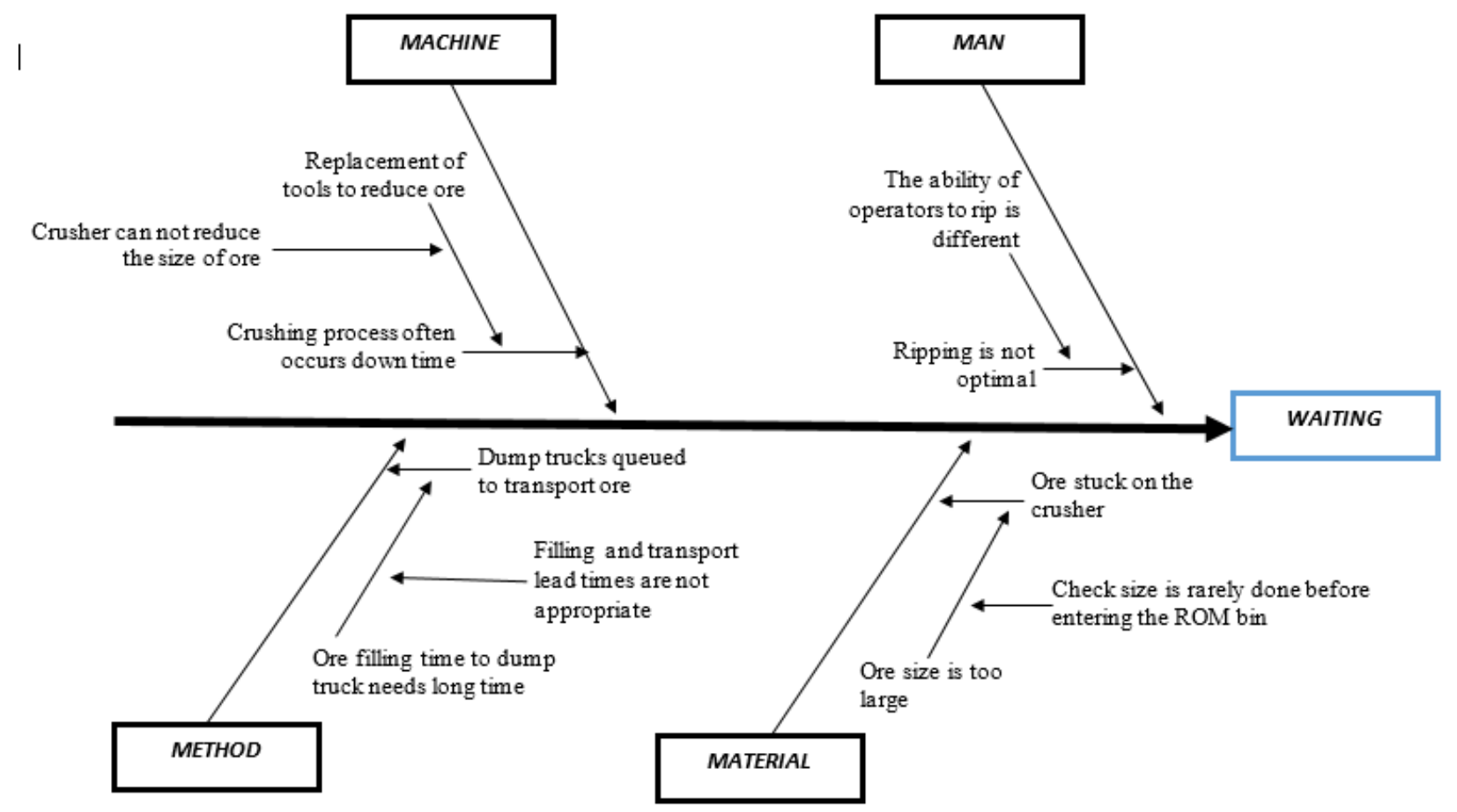

Figure 5. Fishbone Diagram of Waiting

The cause of problems in the machine category is the unplanned shutdown due to frequent device damage.

In the method category, the cause of motion is irrigation time that exceeds the standardized time of the company so that laborers waste time doing movements that should no longer need to be done. The irrigation time that has been set is 120 days. However, the operator still continued the irrigation process for more than 120 days. Even though the gold content that can be absorbed is very little. This activity will only make a waste of time, money, and energy.

\section{c. Waiting}

Waiting is a type of waste that occurs because of something that makes waiting for both the waiting process or the HR waiting without doing any work at all. The root cause of the man category problem that causes waste waiting is less than the optimal operator in ripping. Ripping is the process of breaking up the ore before the irrigation process is carried out to absorb the gold content in the ore. This ripping process is not optimal because the ability of the operator to do the ripping process varies.

For the material category, the cause of waste waiting is the frequent occurrence of ore being held at the crusher because the ore size is too large. The cause of the ore size factor that is too large is due to the lack of checking the size of the ore before entering the ROM bin for later processing using a crusher.

In the machine category, the reason is that there is often a momentary break down because the crusher is not able to reduce the size of the ore. If this happens, then what the production department will do is use tools such as rock breakers to break the large ore rocks. But if the rock breaker is not able to break the rock, then the rock must be removed from the crusher.

The root cause of waste waiting in the method category is dump trucks that queue to transport agglomerates from the results of the OPP stage to be transferred to the stacking area at the HLO stage. The cause of this truck queue is due to the agglomerate filling time being too long. The duration of filling is caused by mismatched lead time in filling and transporting agglomerates so that the root cause in this category of the method is the lead time for charging and transporting agglomerates that are not suitable.

d. Process

The waste Process, in this case, can be interpreted as an excessive process activity that causes a negative impact on the production process. Identify the causes of this waste process by looking at four categories of causes, namely man, material, machine, and method. In the man category, the occurrence of the waste process is due to an operator error in running the process, which is the irrigation process. The operator is said to have done something wrong because the operator did the irrigation time exceeding the specified time which is 60-120 days. However, operators do irrigation more than the specified time because usually with the reason to get maximum results but regardless of the cost, time wasted, and the gold content that can be absorbed is very small. This is due to the absence of written rules on irrigation process standards.

The category of material that causes process waste is ore material that undergoes a reduction process due to its size being too large. This is because the ore does not undergo a checking process first after blasting.

In the machine category, the cause of the problem is crusher inspections that are too frequent. This inspection is done every 3 days because the crushers often experience a decrease in workability. The decrease in the crusher is due to the reduced ability of the crusher sweep so that a large ore size escapes out of the crusher.

The cause of the problem in the method category is the mismatch of processing time from carbon regeneration. 
The $1^{\text {st }}$ International Conference on Business and Engineering Management (IConBEM)

February $1^{\text {st }}$ 2020, Institut Teknologi Sepuluh Nopember, Surabaya, Indonesia

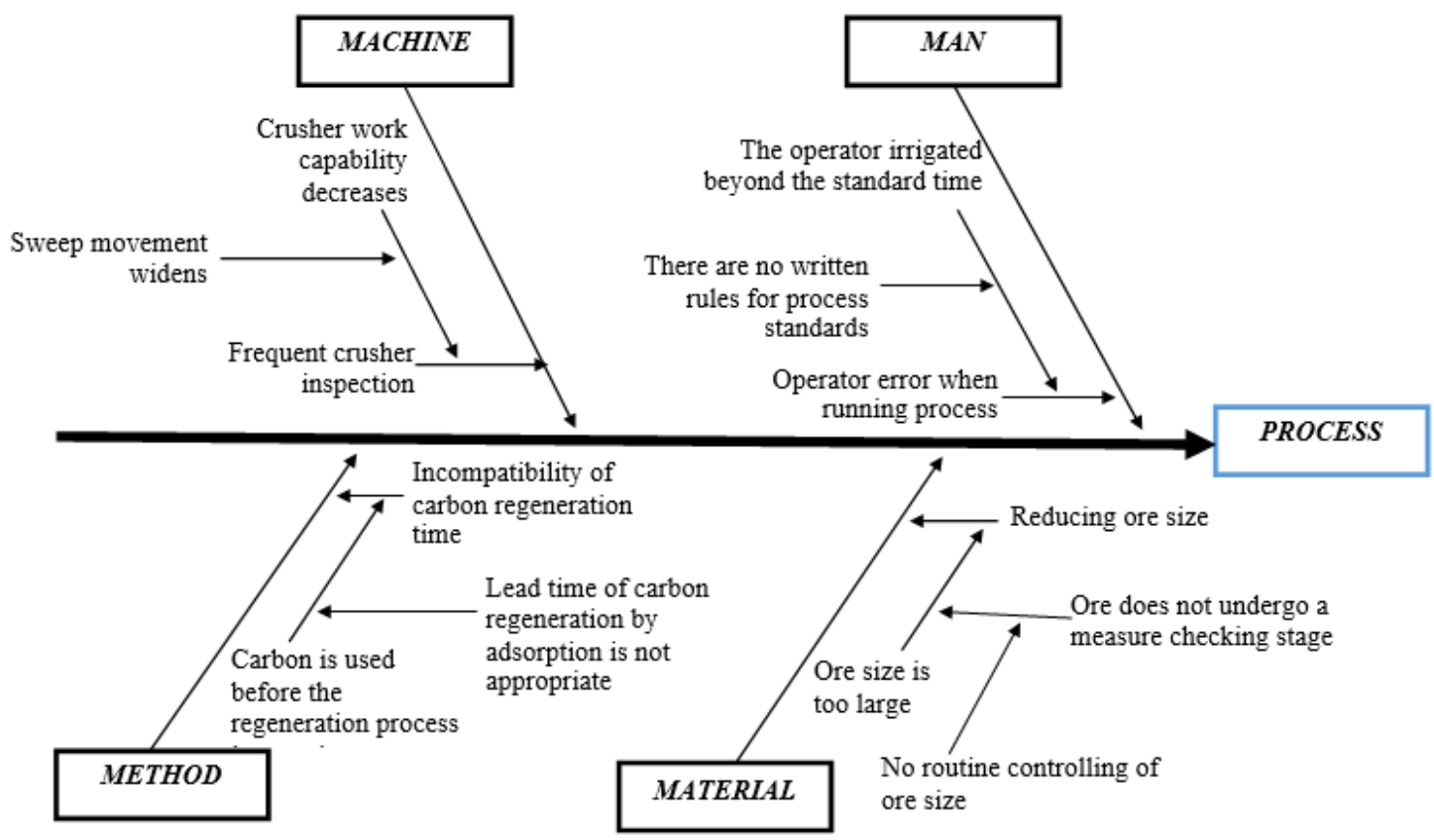

Figure 6. Fishbone Diagram of Process.

The Relationship between Waste

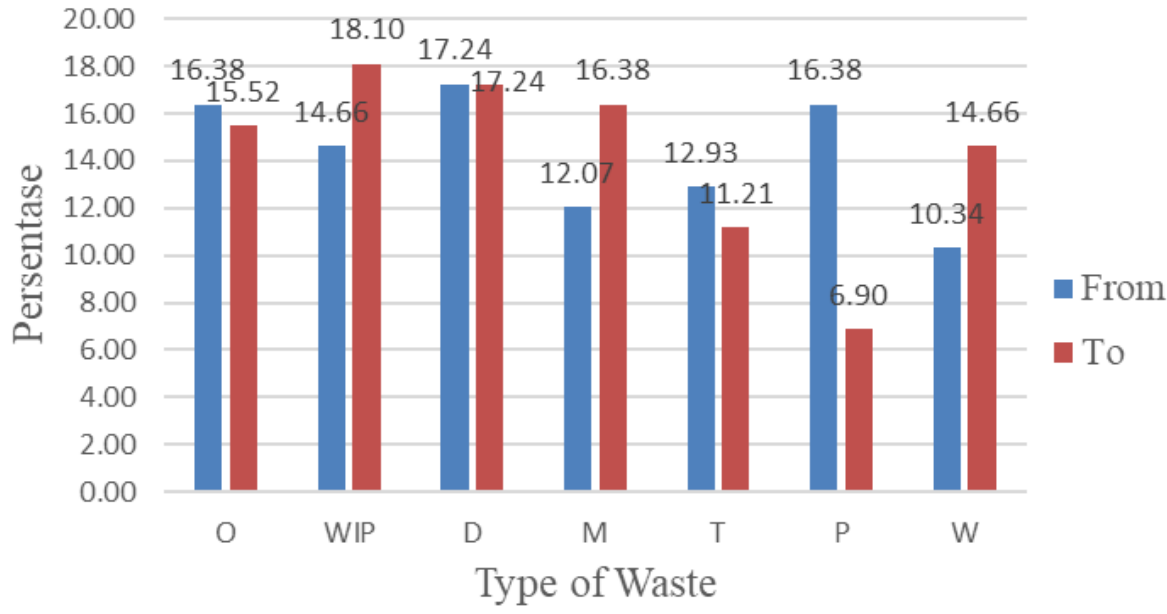

Figure 7. Relationship between Waste

Table 8.

Ranking of Waste Assessment Results.

\begin{tabular}{ccc}
\hline \hline Ranking & Waste & Percent (\%) \\
\hline 1 & Defects & 20.75 \\
2 & Motion & 18.42 \\
3 & Waiting & 17.57 \\
4 & Process & 14.36 \\
5 & Overproduction & 11.36 \\
6 & Work in Process & 10.39 \\
7 & Transportation & 7.16 \\
\hline \hline
\end{tabular}

Carbon is used for the adsorption process of gold content in PLS. However, due to the long carbon regeneration process, which is $22-24$ hours, then before carbon is $100 \%$ regenerated it must be stopped from the regeneration process for the adsorption process. This happens because the lead time regulation between the adsorption process and carbon regeneration is not appropriate or appropriate.

\section{B. Discussion}

Waste Relationship Matrix (WRM) analysis is used to find out how much the linkages between waste occur. The results of WRM analysis can be seen in Figure 7.

Figure 7 shows the percentage of relationships/relationships between waste that occurs in the dore bullion production process. The linkage is divided into 2 namely "from" and "to". "From" shows waste that has an effect or has an effect on other waste. While "to" indicates a waste that is affected or the waste arises because of other waste.

The highest percentage of "from" waste are defects with a percentage of $17.24 \%$. This means that waste defects can influence the emergence of the other six wastes. While the highest percentage of "to" waste is Material Work in Process (WIP) with a percentage of $18.10 \%$. WIP material which has the highest percentage of "to" waste indicates that this WIP material waste is most influenced by the other six wastes. 
The $1^{\text {st }}$ International Conference on Business and Engineering Management (IConBEM)

February $1^{\text {st }} 2020$, Institut Teknologi Sepuluh Nopember, Surabaya, Indonesia

Table 9.

Root Cause of Waste and Recommendations for Improvement.

\begin{tabular}{|c|c|c|c|}
\hline Waste & Category & Causes & Recommendations for Improvement \\
\hline \multirow[t]{6}{*}{ Defects } & Man & Product handling is not appropriate or optimal & Training for employees in material handling (Standardized work) \\
\hline & \multirow[t]{2}{*}{ Material } & Choke material & Controlling regarding ore size composition (Kamishibai tool) \\
\hline & & Dore bullion printing results do not match & $\begin{array}{l}\text { Using a closed mold form so that the gold solution does not } \\
\text { quickly solidify and the bottom mold can be fully filled }\end{array}$ \\
\hline & Machine & Downtime or breakdown occurred & $\begin{array}{l}\text { Meningkatkan the efficiency of the crusher in reducing the size } \\
\text { (TPM tool) }\end{array}$ \\
\hline & \multirow[t]{2}{*}{ Method } & Dore bullion printing process is done manually & $\begin{array}{l}\text { Making an automatic system for filling gold solution into a mold } \\
\text { by adjusting its flowrate over time }\end{array}$ \\
\hline & & Lack of controlling ore size & $\begin{array}{l}\text { Make work procedures about testing ore size or ore size } \\
\text { composition before processing ore (standardized work) }\end{array}$ \\
\hline \multirow[t]{5}{*}{ Motion } & \multirow[t]{2}{*}{ Man } & The operator does not focus on work & $\begin{array}{l}\text { Make standardized work so that each worker can do their own } \\
\text { work without doing work that is not their responsibility. }\end{array}$ \\
\hline & & The operator searches for and retrieves work equipment & $\begin{array}{l}\text { Implement } 5 \mathrm{~S} \text { in the work environment so that the placement of } \\
\text { equipment is more organized to facilitate work }\end{array}$ \\
\hline & Material & Large ore transfer requires a long time & $\begin{array}{l}\text { Controlling ore size before the ore is transferred to the OPP to be } \\
\text { processed (Kamishibai tool) }\end{array}$ \\
\hline & Machine & Unplanned shutdown & $\begin{array}{l}\text { Optimizing the performance of maintenance in carrying out } \\
\text { maintenance and supervision of the performance of the tool }\end{array}$ \\
\hline & Method & Irrigation process exceeded the time set by the production & $\begin{array}{l}\text { Making migrant workers in carrying out the process of irrigation } \\
\text { (standardized work) }\end{array}$ \\
\hline \multirow[t]{4}{*}{ Waiting } & Man & Ripping is not optimal & $\begin{array}{l}\text { There is supervision for the ripping process, and training for } \\
\text { operators in carrying out the process }\end{array}$ \\
\hline & Material & Ore stuck on the crusher & Controlling regarding ore size composition (Kamishibai tool) \\
\hline & Machine & A crushing tool often occurs downtime & $\begin{array}{l}\text { Increase the ability of the crusher to reduce the size or replace the } \\
\text { crusher (TPM tool) }\end{array}$ \\
\hline & Method & $\begin{array}{l}\text { Dump trucks in the queue are loaded out in the process of } \\
\text { filling agglomerates into dump trucks for later transported }\end{array}$ & $\begin{array}{l}\text { Calculate the exact lead time regarding the charging time, } \\
\text { transportation time to the destination. }\end{array}$ \\
\hline \multirow[t]{6}{*}{ Process } & Man & Operator error in the irrigation process & $\begin{array}{l}\text { Implement standardized work by making irrigation process } \\
\text { standards and individual work procedures (TKI) in irrigation } \\
\text { process activities }\end{array}$ \\
\hline & Material & Ore size must be reduced again & Apply ore size controlling activities before use in processing \\
\hline & Machine & Frequent crusher inspections due to reduced ore size & Improve the effectiveness of crusher performance \\
\hline & \multirow[t]{3}{*}{ Method } & \multirow{3}{*}{$\begin{array}{l}\text { Incompatibility of carbon regeneration process time with } \\
\text { adsorption }\end{array}$} & Set the lead time for the carbon regeneration process \\
\hline & & & Increase the amount of carbon \\
\hline & & & Add carbon regeneration vessel \\
\hline
\end{tabular}

The results of waste assessment using WAQ are shown in Table 8 regarding the ranking of waste that occurred. The ranking of waste is useful to help in which waste needs to be eliminated based on its ranking. Here is a waste that has a high percentage and needs to be eliminated:

\section{a. Defects}

The result of the percentage of waste defects is related to the condition of the company and the results obtained are that this waste is in accordance with the conditions that occur in the company with frequent faulty equipment or product failure. For example, related to defect material, ore material from mining results is sent to the OPP to be reduced in size and processed into agglomerates. However, in reality, ore material sent from mining has a uniform or the same size so that when the ore enters the crusher the material will potentially be retained in the tool. Because of this, the crusher cannot move to reduce the size of the ore. In addition, due to this, the next process must stop waiting for the ore to be removed or destroyed using a rock breaker. Moreover, this crushing process is the initial process in processing ore into gold, so that it will greatly affect the subsequent processes. Therefore, this problem needs to be addressed so that the process can run efficiently.

\section{b. Motion Waste}

Motion waste is ranked second. Examples of problems from this waste motion are about material handling. The mining party sends the ore to OPP, but sometimes the ore that is sent exceeds the required size so the mining operator must come again to OPP and do material handling to mining to reduce the size. With great distance, the operator must make excessive movements because the ore crusher or large size reduction is not on the side of the OPP. In addition, operator 
The $1^{\text {st }}$ International Conference on Business and Engineering Management (IConBEM)

February $1^{\text {st }} 2020$, Institut Teknologi Sepuluh Nopember, Surabaya, Indonesia

control rooms are also often seen going down to the production process area to help with work. With a sufficient number of human resources, but in doing a job desk, some

people have to do double work that is not their responsibility. This problem will have an impact on other activities in terms of time and energy efficiency.

c. Waste Waiting

One of the causes of waste waiting is caused by ponding. Ponding is an occurrence of standing water in an irrigation area. If ponding occurs, the irrigation process cannot run smoothly because the flow of the solution that has absorbed the gold content cannot run smoothly into the pool of Pregnant Leach Solution (PLS) or Intermediate Leach Solution (ILS) because of this ponding. Ponding problems are caused by suboptimal ripping ores before the irrigation process begins. So, when the ripping process is less than optimal, ore loosening is also less than optimal, which over time if the ore is flowed by $\mathrm{NaCN}$ flow will continuously form a puddle. To overcome this ponding, the irrigation process must be stopped temporarily which means that the process will automatically stop too. After the irrigation process is stopped, the irrigation pipe is uninstalled. After that ripping is done again so that the ore is in a loose condition again. Furthermore, the production installs or re-installs the irrigation pipe again and continues the irrigation process which had stopped.

\section{d. Waste Process}

This Waste Process arises because of problems with the process of irrigation and carbon regeneration. The irrigation process experienced excessive processing time which is exceeding the maximum standard of 120 days. This excessive process is carried out on the grounds in order to get the maximum gold content. However, when carrying out activities to maximize results, consideration must be given to both negative and positive factors. The irrigation process, which is over 120 days, will absorb very little gold. If this continues it will make the processing time wasted and the costs will increase. The next problem of inefficient processes is the process of carbon regeneration. The carbon regeneration process takes 22-24 hours, while the adsorption process takes 2 hours. However, carbon stays in the adsorption vessel for 12 days. After 12 days, carbon regenerates carbon. From this, it is necessary to find the appropriate lead time between the two interrelated processes.

The four wastes described above require improvement to reduce or eliminate the waste. Based on the root causes of the problems that have been obtained from the results of the Fishbone Diagram analysis, it is used as a way to determine alternative recommendations for improvement in eliminating or reducing the presence of waste. Proposed recommendations that can be given and implemented are shown in Table 9.

\section{CONCLUSION}

From the results of the analysis and discussion carried out in this study can be summarized as follows:

1. Based on the results of the Waste Assessment Questionnaire (WAQ) analysis, the highest-ranked waste is defects of $20.75 \%$, motion of $18.42 \%$, and waiting of $17.57 \%$, and the process of $14.36 \%$.

2. Waste defects that occur are caused by the operator handling the printing of gold manually less precisely so that the printed result is not as desired, the occurrence of choke material, the occurrence of downtime or breakdown due to tool damage, and the lack of controlling the size of the ore before processing.

3. Waste Motion that occurs is caused by operators who are not focused on their work by doing other work that is not their responsibility due to the limitations of competent HR, operators who have to repeat the transfer of ore because the size is not appropriate.

4. Waste waiting that occurs is caused by the operator not ripping optimally so that ponding occurs, the ore is stuck on the crusher which must stop the process, and frequent downtime occurs on the crusher.

5. Waste Process occurs because there is an excessive processing time in the irrigation process that is more than 120 days and a mismatch of the schedule or lead time between the interconnected processes namely carbon regeneration with adsorption.

6. Recommendations for improvement for waste problems that occur in the dore bullion production process, i.e.:

a. Defects

- The Kamishibai tools are applied by controlling the ore size composition to be processed.

- Add an automatic machine/system to fill the gold solution to the mold in an effort to improve the process.

- Increasing the effectiveness of the crusher

b. Motion

- Establish work standardization by making migrant workers in the irrigation process

- Establish work standardization for each individual in carrying out their duties

- Implement 5S in the work environment

c. Waiting

- Controlling ore size

- Total Predictive Maintenance (TPM) by increasing the ability of the crusher to reduce its size

- Calculation of lead time for filling agglomerates into dump trucks until sending agglomerates by dump trucks to the stacking or irrigation area

- Optimizing maintenance performance in conducting surveillance and maintenance of the equipment

d. Process

- Standardized processes regarding irrigation processes

- Standardized work for irrigation operators

- Rearrange the old schedule for carbon regeneration with adsorption

\section{REFERENCES}

[1] Abhishek Dixit, Vikas Dave, and Alakshendra Pratap Singh, "Lean Manufacturing: An Approach for Waste Elimination," Int. J. Eng. Res., vol. V4, no. 04, 2015.

[2] J. Lööw and J. Johansson, "An Overview of Lean Production and its Application in Mining," Miner. Resour. Mine Dev., no. May 2015, pp. 121-136, 2017.

[3] M. Fahad, "Implementation of Waste Assessment Matrix and Line Balancing For Productivity Improvement in a High Variety / High 
The $1^{\text {st }}$ International Conference on Business and Engineering Management (IConBEM)

February $1^{\text {st }} 2020$, Institut Teknologi Sepuluh Nopember, Surabaya, Indonesia

Volume Manufacturing Plant," vol. M, no. May 2015, 2017.

[4] K. A. El-namrouty and M. S. Abushaaban, "Seven wastes elimination targeted by lean manufacturing case study " Gaza strip manufacturing firms "," vol. 1, no. 2, pp. 68-80, 2013.

[5] A. Rawabdeh, "A Model for the assessment of waste in job shop environments," Int. J. Oper. Prod. Manag., vol. 25, no. 8, pp. 800822, 2005.

[6] D. Hines, Peter; Taylor, Going Lean. Cardiff, UK: Lean Enterprise Research Centre.

[7] Yadrifil, "Implementation of Lean Manufacturing System To Eliminate Wastes on The Production Process of Line Assembling Electronic Car Components With WRM And VSM Method," pp. 1153-1169, 2017.
[8] K. Sriwana, "Proposed Improvement of Line Balance Efficiency with Value Stream Mapping and Yamazumi Chart at PT.PAI," vol. 20, pp. 33-44, 2019.

[9] M. Nimisha, Kamath Krishnananda, and A. R. Shabaraya, "Conducting root cause analysis and its implementation: a perspective," Manipal J. Pharmaceutical Sci., vol. 2, no. 2, pp. 21$25,2016$.

[10] M. J. Ershadi and R. Aiassi, "Root cause analysis in quality problem solving of research information systems: A case study Root cause analysis in quality problem solving of research information systems : a case study Mohammad Javad Ershadi * Roozbeh Aiasi and Shirin Kazemi," no. January 2018. 